\title{
A MIDDLE AGE LADY WITH FEVER AND PRODUCTIVE COUGH
}

\author{
A. H. M. THAFIKUL MAZID ${ }^{1}$, MD ROBED AMIN ${ }^{2}$
}

Mrs. M, 75 years of age, Non diabetic, hypertensive and chronic stable angina patient, resident of Lalbagh, Dhaka presented with the complains of high grade fever with chills and rigor for 14 days associated with pleuritic chest pain for same duration and productive cough and progressive worsening dysnoea for 10-12 days. On examination there was features of

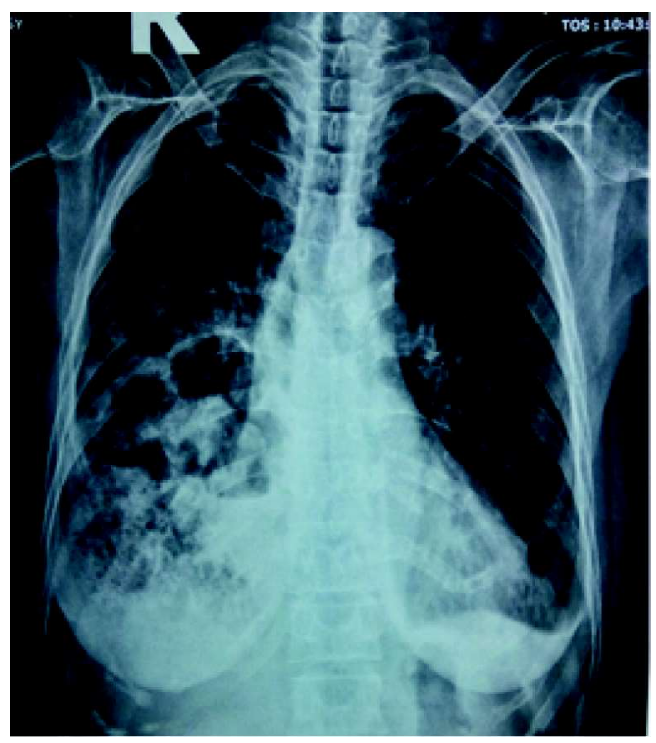

can be detected from evaluation of imaging in abdomen easily, its not that easy from chest imaging. Patient presented with features of cavitary lung lesion (Fig A) later found to have abdominal loop in mediastinum in coronal reconstruction CT scan of chest (Fig B) Part of the Some bowel loops, adjacent to the heart $(\mathrm{B})$, is clearly visible. The right lung is displaced and

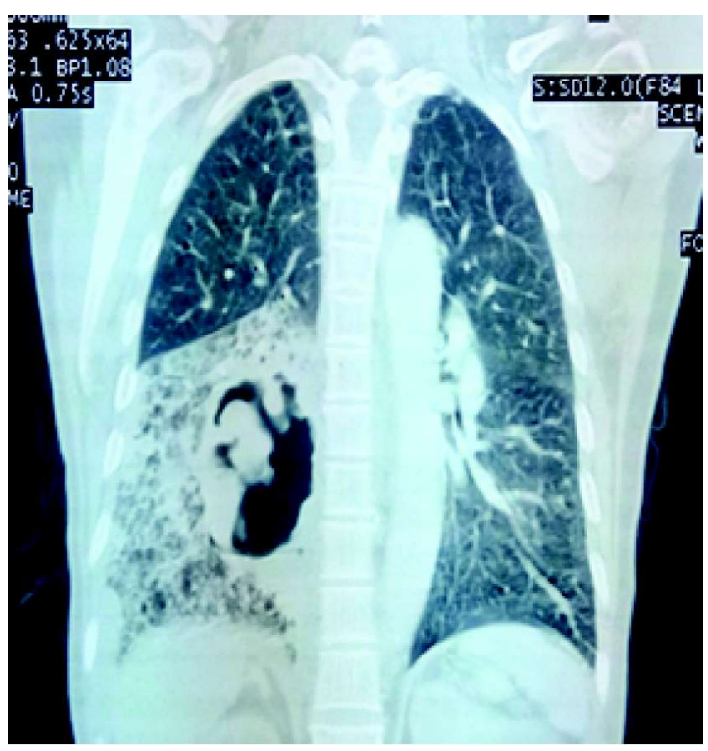

Fig: A. Chest xray revealed features of multiple cavitary lesions while B. CT scan revealed features of consolidation with gas containing loops of bowel with diaphragmatic hernia

consolidation on right sided chest territory and others area with vesicular breath sound and prolonged expiration. She was diagnosed as Cavitary lung lesion with COPD with Hypertension and Ischemic Heart disease. Imaging studies were done including chest $\mathrm{x}$ ray and $\mathrm{CT}$ scan of Chest.

\section{Discussion:}

The abdominal hernia with bowel loop in chest or mediastinum is a rare finding ${ }^{1}$. Although the hernia compressed. Adult bochdalek hernia should be considered as a differential possibility in caviatry lung lesion imaging modality of chest imaging. ${ }^{2,3}$

1. Bianchiet al. Journal of Medical Case Reports 2013,7:125

2. Sridhar AV, Nichani S:Late presenting congenital diaphragmatic hernia.Emerg Med J2004,21:261-262.

3. Wilbur AC, Gorodetsky A, Hibbeln JF:Imaging findings of adult Bochdalek hernias. Clin Imaging, 1994, 18:224-229

1. Medical Officer, Department of Medicine, Dhaka Medical College

2. Associate Professor of Medicine, Dhaka Medical College

Received: 03 September 2018

DOI: https://doi.org/ 10.3329/bjmed.v30i1.39925

Accepted: 05 November 2018

Bangladesh J Medicine 2019; 30 : 50 